\title{
doispontos:
}

\section{Os desdobramentos da psicologia experimental em Moritz, Kant e Kierkegaard}

\author{
The developments of experimental psychology in Moritz, Kant and Kierkegaard
}

\author{
Márcio Suzuki ${ }^{1}$ \\ Professor do Departamento de Filosofia da Universidade de São Paulo - USP ; Pesquisador CNPQ \\ marciosuzuki@usp.br
}

\begin{abstract}
Aux joyeux jours berlinois des nouveaux "alethophiles".
"Para que o efeito de um corpo seja grande, sua massa ou sua velocidade tem de ser grande, ou ambos ao mesmo tempo. Caso aceitemos a força de desejar como a massa da alma, fica claro que nas paixões é empregado um alto grau dessa força: e, consequentemente, nas ações e efeitos das paixões a massa da alma, por assim dizer, é grande. Acabo de mostrar que também a velocidade é muito grande. Consequentemente, é claro que a grandeza dos efeitos da alma surge de suas causas de maneira semelhante aos efeitos dos corpos. Pode-se em geral dizer que as leis das modificações da alma coincidem exatamente com as leis do movimento e, por isso, decorrem exatamente dos mesmos fundamentos distantes. Esses fundamentos teriam, de fato, de ser buscados numa dinâmica geral...”
\end{abstract}

Georg Friedrich Meier ${ }^{2}$

Resumo: Depois de breve contextualização, este texto estuda a herança da psicologia experimental de Christian Wolff em Karl Philipp Moritz, Immanuel Kant e Søren Kierkegaard. Esses três autores transformaram as premissas mais científicas e técnicas da disciplina em formas mais abertas de experimentação romanesca ou teatral.

Palavras-chave: psicologia experimental; Christian Wolff; Moritz; Kant; Kierkegaard.

Abstract: After a brief contextualization, this text presents how Karl Philipp Moritz, Immanuel Kant and Søren Kierkegaard worked, each in their own way, the heritage of Christian Wolff's experimental psychology, transforming its more scientific and technical premises into forms of romanesque or theatrical experimentation.

Keywords: experimental psychology; Christian Wolff; Moritz; Kant; Kierkegaard.

\footnotetext{
O presente trabalho foi realizado com o apoio da Coordenação de Aperfeiçoamento de Pessoal de Nível Superior - Brasil (CAPES) - código de financiamento 001.

${ }^{2}$ Theoretische Lehre von den Gemüthsbewegungen, Halle: Hemmerde, 1759, \$208, p. 210.
} 
Na história da psicologia, Christian Wolff (1679-1754) é unanimemente reconhecido como aquele que procurou introduzir pela primeira vez nessa disciplina o método experimental, tendo antecipado, inclusive, a ideia de psicometria ${ }^{3}$. O interesse de sua iniciativa residiria em ter ele tentado dar a essa matéria o mesmo estatuto que se concedia então à física newtoniana, ciência natural cuja precisão e justeza eram consideradas equivalentes às das matemáticas.

Como a física, a psicologia é para Wolff uma ciência empírica, porque o conhecimento da psique também poderia passar pelo teste da experimentação ${ }^{4}$. O nome mesmo da ciência em alemão pretende dar conta também dessa significação: a psicologia não quer ser apenas uma ciência empírica ou da experiência (Erfahrungsseelenkunde), mas também uma ciência experimental da alma (Experimentalseelenlehre) ${ }^{5}$. Muitos comentários assinalam que quando d'Alembert alude a uma "physique expérimentale de l'âme" no Discurso Preliminar à Enciclopédia, a sua referência é o wolffismo, embora o parágrafo trate da filosofia de Locke. Para se ter ideia do significado do gesto inaugural de Wolff, é ilustrativo compará-lo também à tentativa de Hume de fundar a sua ciência da natureza humana segundo o modelo da física newtoniana. O resultado que se busca nos dois casos é parecido: a filosofia (como ciência da natureza humana ou como psicologia) deve poder alcançar o mesmo grau de precisão e rigor que a física.

Nas hostes wolffianas a confiança na solidez da psicologia como ciência experimental foi de tal ordem, que mesmo um autor bastante receptivo a outras influências como Sulzer tomava como ponto pacífico que a alma, à maneira de um outro objeto físico qualquer, também era suscetível de experimentação. A psicologia, segundo ele, contém

uma descrição distinta e exata de tudo aquilo que nos é conhecido da alma pela experiência. É que os diferentes efeitos da alma foram descritos da maneira mais exata e desmembrados, por assim dizer: depois, pela observação mais exata deles (genaueste Beobachtung derselben) foram dadas explicações distintas dos diferentes efeitos, capacidades e propriedades da alma. Procede-se aqui como na física se procede com as coisas corpóreas, que se aprende a conhecer por meio de experiências e ensaios. Poder-se-ia, portanto, chamar essa parte da psicologia de física experimental da alma [Experimental-physik der Seele] (SULZER, 2014, p. 140) ${ }^{6}$.

É verdade que o desmancha-prazeres Kant veio, mais uma vez, atrapalhar a festa, colocando em dúvida a presunção de cientificidade do conhecimento da alma. Contra todas as supostas evidências, ele mostra, na Crítica da razão pura, que a psicologia não pode ter estatuto científico, faltando-lhe a condição fundamental para tanto: ela não é ciência, porque a alma só se fenomenaliza numa dimensão, a do tempo, jamais podendo ser intuída na tridimensionalidade ou mesmo bidimensionalidade do espaço ${ }^{7}$.

Apesar de seu veto à psicologia científica, Kant conservou a ideia de experimentalismo psicológico, presente e atuante no âmbito da antropologia pragmática, último refúgio para o estudo da alma no sistema crítico. Como se lê na Arquitetônica da Crítica da razão pura, não há nenhum outro espaço para a psicologia empírica no conjunto das ciências a não ser um "lugarzinho" (Plätzchen) no interior da antropologia (AA 03: 548). A antropologia pragmática é concebida, wolffianamente, como o espaço em que é possível e

\footnotetext{
${ }^{3}$ Sobre a importância do filósofo dogmático para o desenvolvimento da psicologia posterior ver ARAUJO, 2012, pp. 1013-1024.

${ }^{4}$ Como escreve Wolff no $\$ 111$ do Discurso preliminar: "Patet Psychologia empiricam Physicae experimentali respondere atque adeo ad philosophiam experimentalem pertinere” (É evidente que a psicologia empírica corresponte à fisica experimental e pertence, nessa medida, à filosofia experimental" (WOLFF, 1732, 51).

${ }^{5}$ Como se lê, por exemplo, no título da obra de Johann Gottlob Krüger Versuch einer Experimental-Seelenlehre, de 1756.

${ }^{6}$ Sulzer escreveu também os Essais de physique apliquée à l’âme (Ensaios de física aplicados à alma) que foram traduzidos e publicados por Samuel Formey em francês nos seus Mélanges philosophiques.

${ }^{7}$ Cf. KANT, Kritik der reinen Vernunft, AA 03: 052. As citações das obras de Kant em alemão se referem à edição das Academias de Berlim e de Göttingen. A numeração segue a convenção adotada entre os estudiosos de Kant: o primeiro número se refere ao volume; o segundo, à página. Não caberia discutir aqui que a razão mais profunda da inaptidão da psicologia para ser uma ciência deriva da dessubstancialização geral praticada por Kant, desde quando leu o Ensaio sobre o entendimento humano de Locke. A alma não é uma substância e, por isso, só poderia ser conhecida pelos seus efeitos, como todas as demais supostas "substâncias".
} 
desejável fazer experimentos a fim de que se afiram as capacidades pragmáticas de cada indivíduo, isto é, as suas forças para ser feliz e também para cumprir com os requisitos da moral. Esse espaço de experimentação aparece de maneira bastante clara também nos cursos de ética, quando antropologia e moral ainda não estão separadas. Num desses cursos se afirma que, diferentemente do que ocorre na Fundamentação e na Crítica da razão prática, a regra não tem valor universalmente condicionante, independemente das disposições do sujeito: "A consideração da regra é inútil, se não se pode tornar o ser humano preparado para seguir regras" (KANT, 2018, p. 87). A antropologia prepara o homem para a execução da lei moral. Assim, se a moral é a parte pura, a antropologia é a parte empírica das duas ciências e, como tal, ela está para a ciência pura, assim como a física experimental está para a física teórica:

Por causa disso, essas duas ciências [moral e antropologia] estão muito relacionadas. Trata-se da mesma coisa que acontece quando a física teórica está relacionada a experimentos, pois também se fazem experiências com seres humanos (KANT, 2018, p. 87).

Os seres humanos podem ser testados, assim como se testa um material ou um dispositivo para ver se pode ser utilizado para um determinado fim. Tomando-se a analogia em sentido literal, corre-se certamente o risco de coisificar a alma, risco este sempre presente na psicologia entendida como ciência. De fato, a ideia de experimentação como submissão da alma humana a testes de verificação foi entendida, por exemplo, por Johann Gottlob Krüger como sendo análoga a experimentos que se podem fazer para entender a fisiologia

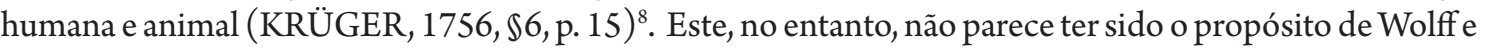
dos wolffianos. É o que se vê em Kant, que se levanta precisamente contra a posição de Krüger, ao afirmar que a experimentação psicológica não pode ter o sentido que este último lhe dá.

O homem não pode ser observado por meio disso [de experimentos]. É bem possível fazer experimentos com animais e coisas, mas não com homens; porque assim que este observa isso, ele faz exatamente o contrário do que se quer dele (KANT, Anthropologie Busolt, AA 28: 1437).

Kant também recusa por isso a distinção que Krüger faz entre "tentativa" (Versuch), em que nada se altera no objeto que se quer conhecer, e experimento (Experiment), que ocorre quando "colocamos a coisa em situações em que normalmente não estariam e, com isso, obrigamos a natureza a nos mostrar aquilo que ela

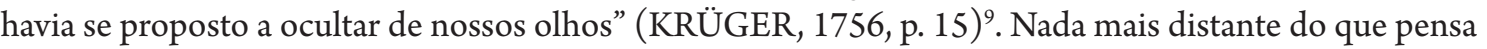
Kant, para quem a dificuldade do experimentieren em filosofia está em que ela deve ser feita sem mudança do estado mental:

Para fazer dela [da psicologia empírica] uma ciência, seria preciso que colocássemos em obra experiências metódicas, quer dizer, por observação e experimentação. A experimentação que eu faço modifica muito meu estado mental, embora eu queira experimentar esse estado imodificado, e não nesse estado modificado (KANT, Metaphysik K 2, AA 28, p. 749).

A impossibilidade de apreender a psique num estado imodificado é, assim, outro fator determinante a impedir que a psicologia empírica se torne ciência ${ }^{10}$. Mas o problema metodológico de apreender os

\footnotetext{
${ }^{8}$ Krüger mesmo admite a "barbaridade" e crueldade dos métodos empregados em fisiologia, para os quais o seu coração é "por demais sensível” (KRÜGER, 1756, \$6, pp. 18-20). A ligação da medicina com a filosofia serviria justamente para indicar um meio prudente (klug) de solucionar o problema" (KRÜGER, 1756, \$6, p. 20). Para uma exposição e tentativa de atenuação da posição de Krüger, ver (STIENING, 2016, pp. 139-144).

${ }^{9}$ Um aspecto fundamental da psicologia experimental, que, entretanto, não cabe discutir aqui, é a grande dívida de Kant para com as descobertas fisiológicas de Krüger e tantos outros, que ele acaba incorporando não só na sua antropologia, mas também, em muitos casos, na sua teoria do conhecimento. A posição de Krüger é tanto mais interessante, quanto, para ele, os estados extraordinários e incomuns que uma modificação do corpo provoca na alma podem ser considerados já "experimentos" da alma em sentido amplo (KRÜGER, 1756, p. 15). O patológico é, portanto, o caminho para compreender o funcionamento da psicologia.

${ }^{10}$ Kant dirá algo semelhante sobre as investigações a respeito dos elementos da razão pura. Tampouco estes podem ser objeto de experimento (Experiment), daí a impossibilidade de transplantar o método do cientista natural para a investigação transcendental (KANT, Crítica da razão pura, AA 03: 013).
} 
estados da alma permanece integralmente o mesmo naquele "lugarzinho" que resta reservado à psicologia empírica dentro da antropologia pragmática. Se a antropologia é a disciplina que em Kant substitui a psicologia empirica no desvendamento da alma humana, a sua prática deve se dar num tempo e espaço determinados, em meio às vicissitudes e contingências da vida vivida, não em condições artificiais em que a alma seria diferente do que é.

A versão mais instrumentalizante que Krüger dá à psicologia experimental não faz certamente jus ao espírito em que foi originalmente concebida por Wolff e desenvolvida pelos wolffianos. Para os que abraçaram a proposta do filósofo de Halle, o adjetivo "experimental" apresenta duas faces, uma menos e outra mais radical, por assim dizer, pois uma se faz dentro dos limites da ciência psicológica, enquanto a outra os extrapola ${ }^{11}$. Ambas, porém, são igualmente interessantes em suas propostas. $O$ espírito que as comanda pode ser dito experimentalista ou ensaísta, palavras que rementem tanto ao caráter científico quanto ao caráter artístico do termo.

Em sua face menos arrojada, ela pode ser explicada assim: para o wolffismo, conhecer a alma implica a passagem do saber histórico ao saber racional, isto é, de um saber natural a um saber técnico ou artificial (künstlich). No caso do conhecimento da psique, tal passagem do natural ao técnico significa a possibilidade ou necessidade de inventar dispositivos pelos quais se possam obter resultados semelhantes àqueles alcançados, por exemplo, pelo telescópio na observação do céu ou pelo microscópio na investigação do organismo. A psicologia experimental assim entendida é responsável por armar a observação, devendo haver uma interação entre o modo de produzir o experimento e o modo de equipar a percepção do observador. $\mathrm{O}$ alcance filosófico disso não é pequeno: diferentemente do que ocorre em tentativas de observação "nua" ou "desarmada" das percepções e ideias da mente, como em Descartes e no método histórico de Locke, no wolffianismo a observação pode e deve lançar mão de instrumentos e artifícios que permitam uma maior e melhor prospecção na alma humana. É aqui que entra uma distinção wolffiana fundamental: no conhecimento da alma existe uma diferença entre observar e experimentar. Como explica o próprio Wolff:

Observação é a experiência que versa sobre fatos da natureza sem as nossas obras.

Experimento é experiência que versa sobre fatos da natureza que não ocorrem senão com intervenção de nossas obras (WOLFF, 1738, \$456, p. 357) $)^{12}$.

Conhecer a psique requer muito mais do que a mera observação. O observador da alma, na verdade, se porta geralmente de maneira passiva, ele não produz nada. Já a experimentação requer, ao contrário, uma produtividade, uma operatividade, "uma intervenção de nossas obras", unicamente pela qual se pode medir a capacidade, a eficiência de uma força ( Kraft), termo que, como se sabe, é usado em alemão também

\footnotetext{
${ }^{11}$ É preciso lembrar que a psicologia experimental é concebida por Wolff como uma ciência que se situa, junto com a psicologia racional, no interior da filosofia, como uma de suas metafísicas especiais (ao lado da cosmologia e da teologia). É no wolffismo que a psicologia se autonomiza, saindo da filosofia e ocupando um espaço seu (apesar das objeções de Kant). Mas ela também ganha outros espaços, como se verá nos exemplos adiante.

${ }^{12}$ Cf. também: "A arte heurística a posteriori extrai a verdade desconhecida quer das observações, quer dos experimentos. Pois conhecemos a posteriori o que conhecemos experimentando (WOLFF, 1738, $\$ 434$ ). Por isso, a experiência consiste, quer no número de observações, quer no de experimentos (WOLFF, 1738, \$456); do mesmo modo, a arte de descobrir a verdade $a$ posteriori deve ser tirada, quer de observações, quer de experimentos. A arte heurística a posteriori ocorre, pois, de duas maneiras, a saber, como arte de observar e arte de experimentar” (WOLFF, 1738, \$457, p. 357). A avaliação de Kant em relação à observação e à experimentação é oscilante, ora tendendo a aceita-la (ver acima nota 7), ora a recusá-la, como no curso de Metafísica Dohna: "A questão última na psicologia empírica é: é possível uma psicologia empírica como ciência? Não - nosso conhecimento da alma é por demais restrito $[z u$ eingeschränkt]. E um conhecimento empírico se torna ciência quando o derivamos de um princípio, procedemos em geral metodicamente pela observação ou experimentação [durch observiren oder experimentiren]; o primeiro é difícil, e o segundo, impossível; pois o experimento que fazemos já modifica o nosso estado de ânimo" (KANT, AA 28: 679). Como a alma ou o estado de ânimo nunca é nada fixo, tentar captá-lo por meio de um experimento já é introduzir uma modificação nele.
} 
para falar das faculdades da alma (Vermögen). Só por isso já se vê como a psicologia empírica de Wolffé fundamental para a ideia de uma crítica dos poderes da mente de Kant.

Na vertente mais arrojada, o termo "experimental" será associado a forma ou formas de experiência artística e literária. A arte, mas principalmente a literatura, passa a ser explorada pelos "físicos da alma" como meio privilegiado de acesso à psique. Essa questão será discutida brevemente a seguir a partir do modo como três autores, Moritz, Kant e Kierkegaard concebem o conhecimento da alma, valendo-se da técnica romanesca ou teatral.

\section{Moritz}

Essa dupla maneira de atuar da psicologia empírica pode ser encontrada na produção do escritor Karl Philipp Moritz, que aliou ao seu trabalho de "psicológo experimental" a sua atividade como romancista. Tendo passado por vivências altamente traumáticas em sua infância e juventude, na própria família, no lar adotivo para onde foi transferito e, sobretudo, nos estabelecimentos de ensino por que passou, Moritz começou a elaborar estratégias, como educador, para aliviar o sofrimento de crianças e adolescentes em idade escolar. Constatada a dificuldade que muitas pessoas têm de chegar sozinhas ao bom conhecimento de si, a um conhecimento que lhes permita o desenvolvimento de suas aptidões (a inibição, como outras paixões, sendo em geral mau conselheiro), uma forma de contorná-la é criar dinâmicas pelas quais elas possam trocar suas experiências, sem que se sintam observadas ou invadidas em sua intimidade. É preciso conquistar a confiança delas para que possam se abrir (a confiança construída é a condição sine qua non para que o observado possa se revelar ao observador). No ginásio do Graues Kloster em Berlim, onde permaneceu de 1778 a 1780, e, posteriormente, como diretor de ginásio em Hamburgo, Moritz incentivava, por isso, os seus alunos a escrever, anonimamente, os problemas pelos quais estavam passando ${ }^{13}$.

Essa mesma estratégia será aplicada quando começa a dirigir o Magazine de psicologia experimental (Magazin zur Erfahrungsseelenkunde, 1783-1792). Ali ele encorajava os leitores a enviar tudo o que julgassem interessante do ponto de vista psicológico (casos, anedotas, sonhos etc.), mantendo a fonte sob sigilo. Uma recomendação importante dizia que as contribuições deveriam conter apenas o relato do sucedido, abstendo-se os colaboradores de emitir interpretações ou juízos de valor sobre ele. Essa prática daria margem a que os leitores tirassem suas próprias conclusões, sem terem de se submeter a "lições" ou a uma "moral da história".

Por ocasião de uma festa de jubileu do ginásio de Werder em 1782, Moritz redige um opúsculo que endereça ao seu diretor, Gedike, e que pode ser considerado uma espécie de "programa” a ser levado a cabo na psicologia experimental. Ele lembra que a criança aprende muito cedo a balbuciar agradecimentos e votos dos quais não compreende absolutamente a motivação, isto é, ela aprende a dissimular antes mesmo de saber que existe a dissimulação e que dissimular é um vício. Essa é uma primeira cortina que separá a criança do observador (MORITZ, 1782, p. 4). Outra dificuldade é encontrar médicos que sejam para a moral o que verdadeiros médicos são para o corpo. $O$ tratamento paliativo é: que os observadores do coração humano façam relatos para uma psicologia experimental. Mas quem ousará publicar as observações que fez em relação aos amigos, parentes, conhecidos etc.? (MORITZ, 1782, p. 6). O anonimato seria a solução.

\footnotetext{
${ }^{13}$ Seja permitido retificar aqui uma informação do posfácio à tradução brasileira do romance Anton Reiser. Ali se afirma que Moritz trabalhou no famoso Philantropinum, escola que Basedow fundou em Dessau. Na verdade, por motivos de saúde, ele não pôde assumir o cargo. Como quer que seja, é muito significativo que Moritz tenha mantido contatos com esse centro educacional, que na época era o mais avançado pedagogicamente da Alemanha.
} 
Um longo trecho desse opúsculo sobre as Perspectivas para uma psicologia experimental é dedicado ao problema da necessidade e da dificuldade de se fazer observações sobre si, e no momento mesmo em que a alma é tomada de algum pensamento ou emoção. $O$ texto merece ser citado na íntegra:

Ele [o observador do coração humano] deveria estar atento à sua vida real presente; teria de notar o fluxo e o refluxo que dominam o dia inteiro o seu interior, e a diferença de um momento em relação a outro; ele teria de tirar tempo para si a fim de escrever a história de seus pensamentos, e fazer de si mesmo objeto de suas mais detidas observações; ele não precisaria estar isento de todas as paixões violentas, e sim entender a arte de sair subitamente, em muitos momentos da vida, do turbilhão de seus desejos, para desempenhar durante certo tempo o papel de observador, sem se interessar o mínimo por si mesmo. Da vida dos homens cuja história é descrita nós conhecemos apenas a superfície. Vemos bem como os ponteiros giram no relógio, mas não conhecemos o mecanismo que o move. Não vemos como as primeiras sementes das ações dos homens se desenvolvem no mais íntimo de sua alma. Se só muito raramente observamos isso em nós, então muito menos nos outros. Com isso não está decidido que possamos notá-lo. Este é um campo ainda por desbravar. Milhares de observações já feitas aqui foram tiradas apenas da superfície, e não extraídas dos recantos mais íntimos da alma. Assim, alguns que refletiram sobre sua alma, fizeram-no talvez somente numa idade em que suas paixões já estavam mais tranquilas, e uma vaga lembrança geral era o fundamento de suas observações. Poucos talvez tenham se dado o tempo de observar a própria alma quando ainda estavam justamente em meio do maior exercício e atividade. É claro que fazer observações sobre si mesmo pode estar ligado a uma ideia repugnante em outros indivíduos; e não há como evitar a ideia de que se atribui uma importância grande demais à própria pessoa para querer ser objeto dessas observações. - Mas pode isso ser feito por um outro? Podemos olhar na alma de um outro como na nossa? E quando dissecamos o estado de nossa alma para bem dos outros, não nos sacrificamos quase como aquele que depois da morte se torna útil aos outros homens pela dissecação de seu corpo? Mas se, por exemplo, numa hora de descontentamento conseguimos nos elevar uma vez apenas acima de nós mesmos a ponto de refletirmos sobre nosso descontentamento, essa reflexão é certamente mais interessante do que quando ocorre somente poucos dias depois, porque com o descontentamento também desapareceu de novo em grande parte a imagem que ele deixou na alma. Quadros fiéis que nos esboçamos da própria alma sempre merecem a maior atenção.

Ora, assim o observador dos homens deveria partir de si mesmo, e suas observações poderiam passar pouco a pouco ao rosto, à linguagem, à ação de crianças, jovens, homens e velhos. Da história secreta de seus próprios pensamentos ele poderia, pelo rosto, linguagem, ação, aprender a inferir sobre a alma de outros (MORITZ, 1782, p. 16).

O texto mostra a posição mais radical de Moritz: os inúmeros relatos que podem ser coletados pela psicologia experimental são de fundamental importância para o conhecimento da alma em geral, mas eles, no fundo, não substituem o conhecimento que o homem deve procurar ter de si mesmo, porque este é também a condição de conhecimento com profundidade dos outros. A dificuldade da observação psicológica, como explica, é dupla: captar a emoção no calor da hora, mas ao mesmo tempo ter recuo suficiente para observá-la com frieza. O observador tem de estar como que o dia inteiro à disposição dessa prática de prestar atenção a si mesmo no momento em que sucede algo de trivial, de inesperado, de estranhamente recorrente, pronto a perceber o quanto tem de responsável no acontecimento e na sua reação a ele. E um diário, um conjunto de anotações sobre os eventos banais ou significantes, pode revelar ao sujeito a trajetória da sua vida.

Essas ideias sobre a psicologia experimental são importantes para a própria carreira de Moritz como escritor, elas funcionam, por assim dizer, como embasamento para a sua concepção do "romance psicológico", gênero com o qual procura caracterizar a sua obra autobiográfica Anton Reiser, cujo material foi tirado em grande parte do diário que manteve em sua juventude (MORITZ, 2019). O hábito da auto-observação pode acabar se consubstanciando numa "história dos pensamentos" do sujeito, na qual ele reconhece a sua trajetória, o próprio modo de sentir e agir.

O romance de Reiser contaria, nas palavras do narrador, a "história interior de seu espírito" (innere Geschichte seines Geistes). A expressão é altamente significativa no horizonte da psicologia experimental, pois ela remete a uma outra expressão fundamental, utilizada por Hermann Samuel Reimarus. Herder foi certamente fundamental para que Moritz entendesse o que é um romance autobiográfico como uma espécie 
de laboratório de prospeção da alma ${ }^{14}$, mas é na interessantíssima Lógica de Reimarus que se formulou pela primeira vez a ideia de que é preciso escrever uma história completa da alma (völlige Seelengeschichte):

Se observássemos e anotássemos mais diligentemente tais casos ordinários ou extraordinários em nós ou em outros, nós poderíamos chegar finalmente a uma experiência mais completa ou uma história da alma, que ainda nos falta agora [....] (REIMARUS, 1766, \$ 90, p. 83).

Moritz entende o seu romance autobiográfico como uma libertação pessoal que se inicia com a redação de seus diários. A obra servirá também para que o leitor em geral, mas principalmente os educadores saibam como lidar melhor com os jovens entregues a seus cuidados. A história da alma individual assim revelada entra para o acervo de conhecimento da psicologia humana. História e literatura fazem parte da "história interior do homem":

Comparações entre diferentes personagens da história, e seu comportamento em casos quase semelhantes. Caracteres e modos de pensar de romance particularmente bons e peças dramáticas, como as shakesperianas, que são uma contribuição para a história interior do homem [innere Geschichte des Menschen] (MORITZ, 1782, p. 10).

Na história de Anton Reiser, assim como na de Moritz, o teatro ocupa uma posição central. Sabe-se pelo Anton Reiser o quanto Moritz sofreu com sua paixão desmedida pelo teatro. No romance, um dos maiores infortúnios do jovem Anton se prende à sua tentativa incessante de imitar e se identificar com outros (o pastor, o pregador, o professor, o ator, os heróis ficcionais etc.), na busca constante de apagar a sua vida miserável pela apropriação da figura idealizada do outro. Mas não há escapatória, os homens estão condenados a viver num eterno jogo de cena, numa espécie de flagelação interminável que as personagens costumam se infligir atribuindo papéis uns aos outros. Papéis de figurantes, porque estão sempre em disputa pelo papel principal (como ocorre com frequência com o próprio Anton). A tarefa da psicologia empírica consiste em saber ensinar como o indivíduo deve abdicar dessa busca por um papel e se converter num observador frio, que participa do comércio entre os homens mais como aquele que se coloca na plateia do que como aquele que interage com eles. No grande palco do mundo é melhor não ter papel algum, e observar com frieza e serenidade tudo o que se passa na grande encenação. A grande questão psicológica é como se tornar um observador frio:

Mas quem dá ao observador dos homens sempre aquela frieza e serenidade da alma de observar tudo o que ocorre como num espetáculo [Schauspiel] e as pessoas [Personen] que o afligem como atores? De fato, e se ele mesmo não estivesse envolvido na encenação [im Spiele], e não ocorresse nenhum ciúme entre os figurantes [Rollenneid]? - Mas o que alguém deve fazer se é oprimido pelos homens ou pelo seu destino e não consegue ir além? Há algo melhor e nobre do que se colocar além desta terra e além de si mesmo, como se fosse, por assim dizer, um outro ser diferente de si mesmo, que, numa região mais elevada sorrisse de todas as coisas - e dessa maneira sobre si mesmo, sobre suas próprias queixas e molésticas - que deleite, que elevação ao criador universal do todo!

Tão logo vejo que ninguém quer me dar um papel, eu me coloco diante da cena e sou um observador tranquilo, frio. Assim que meu próprio estado se torna pesado, deixo de me interessar por mim mesmo e me considero como objeto de minhas próprias observações, como se fosse um estranho, cujos lances de sorte ou infortúnio eu ouvisse narrar com uma atenção impassível (MORITZ, 1782, p. 19-21).

O movimento interno do Anton Reiser, espelhando a vida de Moritz, pode ser descrito como um distanciamento do universo teatral em direção ao universo do romance, como um gradual afastamento das paixões do ator para a do observador e do narrador. A recaída, por certo, anda sempre à ronda, mas a esperança de libertação também nunca é abandonada. Como se lê nesse trecho, Moritz tem no horizonte o ideal do sábio estóico, daquele indivíduo que é capaz de se colocar "além dessa terra e de si mesmo", numa região mais elevada e nobre, de onde pode observar compassivamente todas as coisas terrenas.

${ }^{14}$ Sobre a importância do romance na psicologia herderiana, ver o estudo de TOLLE, 2016, pp. 60-69. 


\title{
Kant
}

Embora tenha recusado cientificidade à psicologia empírica (e também à racional), Kant conservou os preceitos "experimentalistas" do wolffismo, o que pode ser notado pela sua proximidade com as ideias de Hermann Samuel Reimarus. Na sua Lógica, Reimarus retoma a distinção wolffiana entre observação e experiência ${ }^{15}$, introduzindo, porém, a ideia de conhecimento pragmático, de grande repercussão depois ${ }^{16}$. Enquanto Wolff descreve a passagem do conhecimento comum ao conhecimento filosófico como passagem do conhecimento histórico (historisch) ao conhecimento científico ou erudito (gelehrt), Reimarus diz que a generalização da observação ou experiência comum se dá pela passagem do conhecimento histórico a um conhecimento pragmático, o que significa dizer que essa generalização não se faz apenas em vista da obtenção de um ganho teórico, mas em benefício dos homens:

\begin{abstract}
As observações e experimentos são, ou meramente históricos, quando nos mantemos no que é ou ocorre realmente, e talvez ainda não saibamos para que essa experiência possa ser útil; o que, por isso, não precisa ser imediatamente considerado uma brincadeira inútil. Mas quando convertemos o conhecimento obtido do real num conhecimento geral ou então o aplicamos para o proveito do gênero humano, então essas observações e experimentos são pragmáticos (REIMARUS, 1979, \$233, pp. 233-234).
\end{abstract}

Essa precisão conceitual de Reimarus é, sem dúvida, importante para se compreender melhor que a aplicação do método experimental da física à alma não foi entendida em termos meramente teóricos, mas pragmáticos. Observação, experimentação, compilação de casos são os meios de constituir um repertório dos modos de agir da alma úteis e não nocivos para os homens. Este é o sentido de uma história completa da alma para Reimarus:

Quando aplicamos a arte da experiência dos corpos à alma humana, em primeiro lugar têm de ser diligentemente observados aqueles casos ora comuns, ora extraordinários, nos quais se deve conhecer clara e distintamente o que há e ocorre na alma, a fim de alcançar uma história completa da alma (REIMARUS, 1979, \$ 231, p. 244).

Essa ligação entre uma história da alma e seus efeitos pragmáticos reaparece em Ernst Platner, que tem Reimarus em alta conta, chamando-o de "meu amigo" (PLATNER, 1977, p. XIII). A "história pragmática da faculdade humana de conhecer" de Platner influenciará diretamente a "história pragmática do espírito humano", de Fichte, para quem o Wissenschschatslehrer deve ser descrito como um "historiógrafo do espírito humano" ${ }^{17}$. Kant marca, no entanto, a sua diferença em relação à proposta de Platner segundo a qual, dada a união entre alma e corpo, o médico também pode e deve fazer incursões na psicologia e trabalhar conjuntamente medicina e filosofia ${ }^{18}$. Com isso, a antropologia kantiana restringe bastante a possibilidade de transposição dos métodos naturais para o conhecimento humano, impedindo que a psicologia empírica se transfomre numa "fisiologia do sentido interno", conforme se lê na Crítica da razão pura (AA 03: 266).

\footnotetext{
15 "Aquelas experiências de casos que ocorrem na natureza sem nossa iniciativa, se chamam observações [Beobachtungen] ou observationes. Mas experiências de casos que surgem por nossa iniciativa, se chamam experimentos [Versuche] ou experimenta" (REIMARUS, 1979, \$222, p. 234).

${ }^{16} \mathrm{O}$ termo pragmático aparece já nos Princípios da filosofia moral de Baumgarten, manual que Kant utilizava para seus cursos sobre essta disciplina. O pragmático, explica Baumgarten, é aquilo que é "fértil em deduções de corolários práticos, isto é, aquilo que é porismático" (BAUMGARTEN, 2014, \$90, p. 85).

${ }^{17}$ Cf. PLATNER, 1977, \$ 11, p. 9 e FICHTE, GA, I, 2, p. 147. Sobre a importância de Platner para a filosofia de Fichte (que dedicou muitas aulas aos Aforismos filosóficos do médico), ver o texto de GARCIA, "Ernst Platner e a história pragmática da alma", neste volume.

18 “Tudo depende do que se entende por filosofia. Por ela não concebo nada outro que a ciência do homem e de outros corpos e espíritos que tenham uma relação com sua natureza e um referimento a sua felicidade. Segundo esse conceito, a medicina seria manifestamente (e creio que todas as ciências propriamente ditas o sejam) uma parte da filosofia. O homem não é só corpo, nem só alma; ele é a harmonia de ambos, e o médico pode, me parece, se restringir tão pouco àquele quanto o moralista a esta. Acredito, entretanto, que os filósofos morais saibam mais sobre o corpo do que os médicos sobre a alma; pois ainda se considera que o conhecimento do corpo humano faz mais parte da filosofia do que a investigação da alma do sistema da arte médica" (PLATNER, 1772, p. X; p. III-IV).
} 
Platner teria sido um daqueles que não percebeu a diferença entre uma antropologia fisiológica e uma antropologia pragmática ${ }^{19}$. A despeito disso, a antropologia pragmática kantiana conserva dois aspectos essenciais da psicologia experimental alargada dos wolffianos: como arte da prudência, ela deve ajudar os homens na busca da felicidade e um dos meios indispensáveis para isso é lhes apresentar um repertório dos conhecimentos significativos que possam dar meios a que se transite com mais desenvoltura pelo mundo.

Em 1783, Moritz envia a Kant o seu opúsculo sobre as Perspectivas para uma psicologia experimental junto com os dois primeiros volumes da sua Revista de psicologia empírica. As propostas de Moritz e Kant têm, com efeito, muitos pontos em comum ${ }^{20}$, mas também grandes diferenças. A principal delas se refere à observação de si, que é, como se viu, o foco principal da psicologia moritizana. Kant a desaconselha por ser ela uma porta aberta ao delírio e ao misticismo, como também prejudicial à saúde e ao desempenho pragmático. A introspecção, os diários, as confissões não servem, por isso, como experiências de autoconhecimento, assim como os romances, que reforçam a passividade, não a atividade da alma. Por outro lado, assim como em Moritz, o mundo aparece a Kant como um grande teatro e é impossível escapar à dissimulação com que nele se joga o tempo todo; contrariamente, porém, ao que afirma o psicólogo experimental, a grande encenação tem um valor positivo, ela faz necessariamente parte do processo da cultura e sociabilidade humanas. Atuando como um diretor teatral, como um metteur en scène, a natureza faz com que os homens se tornem atores em sociedade, a despeito deles mesmos, porque é por meio dessa ilusão teatral que ela põe a humanidade no caminho de uma moral cada vez mais pura.

Não seria distorcer o pensamento antropológico de Kant dizer que os homens podem ser divididos em bons e maus atores, e o antropólogo pragmático, para fazer frente a esse dom que a natureza distribui entre os homens, deve ser ele mesmo conhecedor da arte teatral, e seu praticante, a fim de poder desenvolver em seus alunos esse talento natural que lhes será útil na vida. Kant, com efeito, conhecia muito bem a arte teatral, principalmente as técnicas do ator. É certamente divertido imaginá-lo a ensinar a seus alunos truques bastante específicos da arte do comediante, mas isso era necessário, já que eles precisariam dessas regras para não serem inibidos e não se darem mal na vida. Não só isso: o próprio trabalho de "pesquisa de campo" do antropólogo pragmático, que consiste em colher conhecimentos no mundo, também deve se valer desses artifícios teatrais. É que os homens, principalmente nas esferas mais altas, sabem dissimular, e dissimular muito bem ${ }^{21}$.

Nos Cursos de Antropologia e nas Reflexões Kantianas aparecem recorrentemente referências a uma discussão central para a teoria teatral e para a arte do comediante no século dezoito, discussão esta em que se perguntava se $\mathrm{o}$ ator deve ser dotado de um talento natural para sentir as paixões que deve representar, ou se deve ser um ator frio, distante. Kant trata esse tema de maneira muito viva, partindo de um episódio, o da "atriz sem coração". A anedota se refere a uma cantora de ópera que não consegue imprimir a devida

\footnotetext{
${ }^{19} \mathrm{O}$ fulcro da crítica de Kant à antropologia médico-filosófica de Platner está em que esta esquece o ensinamento pragmático de Reimarus, sendo menos uma antropologia para o mundo do que uma antropologia ainda presa à escola: "O nome geral que usamos para denominar o conhecimento do homem é antropologia, que não é lecionada em nenhuma outra academia. Platner escreveu uma antropologia escolástica. Nós, porém, não temos outro propósito senão o de extrair regras da diversidade que percebemos no homem; pois, por mais que os humores humanos pareçam ser, indiscutivelmente, diferentes, aqui há, entretanto, mais regularidade do que se poderia pensar" (KANT, Menschenkunde, AA 25: 856). Em vínculo com essa censura, o curso de Antropologia Friedländer condena Platner por ter se afastado das máximas de prudência (Klugheit) e ter se deixado levar pela especulação: "Todas as antropologias até agora existentes não tiveram a ideia que temos aqui diante de nós. Tudo o que não tem relação com a conduta prudente dos homens não faz parte da antropologia. Só faz parte da antropologia aquilo que pode admitir de imediato um uso prudente na vida. Tudo aquilo de onde surgem as ideias pertence à especulação e não à antropologia, tal como o fez Platner" (KANT, Antropologia Friedländer AA: 25: 472).

${ }^{20}$ Sobre a proximidade entre eles, ver SPEZZAPRIA, 2015, pp. 131-132.

${ }^{21}$ As técnicas do comediante examinadas detalhadamente por Kant e sua importância para a antropologia pragmática são objeto de um estudo do autor intitulado Des Herrn Professors Kants Paradoxon des Comoedianten (SUZUKI, 2018, pp. 395-418). A tese geral desse estudo, com uma pequena inflexão, é resumida a seguir.
} 
paixão à personagem que deve representar, a de uma mulher profundamente ferida pelo abandono do amante infiel. Quando perguntam à cantora se ela não é capaz de sentir uma dor intensa pela perda do amado, a atriz responde simplesmente que ela procuraria um outro amante. A anedota foi originalmente utilizada para mostrar a falta de vocação teatral daqueles que não tem talento natural, mas Kant inverte o sinal, passando a usá-la como argumento a favor da frieza do ator. Existe uma diferença, diz Kant, entre "vivacidade" (Lebhaftigkeit) e afeto; o ator pode ser vivo, mas deve ser sem afeto. Quanto mais livre de afetos e de paixões, mais ele desempenha bem o seu papel.É também dessa mesma maneira que o indivíduo precisa agir em sociedade ${ }^{22}$.

As regras de "direção" do ator ocupam um lugar único em meio às regras pragmáticas. Como não se pode conhecer por que motivos internos os homens pautam suas ações, não há como prescrutar o que os leva a agir de uma maneira ou de outra. A antropologia não é uma ciência, tampouco como o é a psicologia. Não há, além disso, uma fisiognomonia, uma ciência capaz de reconhecer na face das pessoas o caráter delas, como imaginava Lavater ${ }^{23}$. Kant é levado então a explicar, através de exemplos, a função antropológica incontornável da arte do ator: não havendo meios seguros de conhecer o interior do homem, é preciso se familiarizar mais e mais com as técnicas do comediante para, a partir da capacidade de mimetização dos gestos, da fala, isto é, a partir de uma imitação do exterior, chegar àqueles móbeis que comandam cada uma das ações humanas. Aprender as regras da pantomima é, por isso, indispensável.

A arte do ator constitui, nesta medida, o suplemento para a ausência de regras de observação claras e precisas da conduta de vida em sociedade. É pelo arremedo da fachada que os homens vão aos poucos entrando nos aposentos internos da moral. A encenação teatral do mundo constitui um análogo da virtude, diz Kant. Mas a radicalidade com que isso é apresentado merece atenção: é possível dizer que o ideal do indivíduo assim esboçado pela antropologia pragmática é a capacidade que se pode chamar de polipragmática. Esta seria a destreza de se colocar em qualquer disposição de espírito, em qualquer afeto ou paixão, pela simples imitação exterior desse afeto ou paixão, sem que se esteja realmente tomado por aquele afeto ou paixão. $O$ indivíduo que é capaz de imitar assim as outras paixões sem cair nelas é o que Kant chama, de maneira positiva, um homem sem caráter. Diz ele:

Alguns têm um instinto poético, isto é, eles precisam criar poeticamente [dichten], quer consigam, quer não, quer tenham talento, quer não. Um tal indivíduo tem uma disposição de ânimo [Gemüths Beschaffenheit] muito peculiar, ele pode assumir todos os caracteres, mas não ter caráter algum (KANT, Anthropologie Parrow, AA 25: 444).

O antropólogo pragmático, o observador dos homens, tem de possuir essa habilidade polipragmática, que não pode ser adquirida por regras pré-fixadas, mas que pode ser de algum modo aprendida pela técnica do ator. Kant se refere a isso quando afirma sobre o observador pragmático:

Temos, portanto, de observar o homem sem nos dar de modo algum o aspecto de observador, tendo também de nos dissimular. É preciso se portar como se a fala saísse sem nenhuma cautela e ao mesmo tempo prestar bem atenção em tudo o que os outros dizem. Mas é sempre difícil conhecer os homens enquanto se observam suas ações, porque isso exige um observador cultivado e agudo (KANT, Menschenkunde, AA 25: 930-31).

É por certo surpreendente notar que a antropologia pragmática considere a ação humana a partir das mais refinadas técnicas da arte do ator no século XVIII. A seguir os seus preceitos, o homem tem de cumprir os mesmos requisitos que Diderot exigia do grande ator no seu Paradoxo do comediante, isto é, nada menos que falta de caráter, condição imprescindível para que ele possa se colocar no lugar de qualquer caráter. Essa

\footnotetext{
${ }^{22}$ Para o leitor interessado, seguem algumas passagens em que Kant trabalha com a arte do ator: Anthropologie Collins, AA 25: 81 e segs., AA 25: 165, 308 e segs; Anthropologie Friedländer, AA 25: 478; 667 e segs., Anthropologie Pillau, AA 25: 827; Menschenkunde, AA 25: 1116 e segs; Rx 1490, AA 15: 844; Rx 1514, AA 15: 844

${ }^{23}$ Sobre a fisiognomonia, ver KANT, Anthropologie Parrow AA 25: 347, 433, 439 e segs.; Anthropologie Pillau AA 25: 826-27; Menschenkunde, AA 25: 1117-19; Anthropologie Mongrovius AA 1378-80.
} 
proximidade é tanto mais surpreendente, porquanto Kant não pôde conhecer o Paradoxo do comediante de Diderot, divulgado na época apenas para o pequeno público seleto da Correspondência literária, filosófica e literária de Grimm. Mas Kant pode ter conhecido a teoria do ator frio por outros canais, principalmente L'art du théâtre a Madame..., de François Riccoboni, que foi uma fonte importante também para o texto de Denis Diderot.

\section{Kierkegaard}

A posição do observador na psicologia empírica e na antropologia pragmática demanda técnicas próprias. No caso de Kant, para que as pessoas não se sintam observadas; no caso de Moritz, também. Para este, os seus alunos e os seus leitores tinham de sentir confiança no psicólogo, e a regra de ouro nesse caso era o sigilo. Os alunos e leitores podiam enviar suas observações, suas inquietações, seus sofrimentos, sem revelar quem eram.

Quando se passa à psicologia experimental de Kierkegaard, o problema é saber o que ele conhecia da psicologia de Wolff e dos wolffianos, mas é preciso não esquecer que o livro A repetição tem por subtítulo: Um ensaio em psicologia experimental. E examinando, por exemplo, os traços com que ele caracteriza seu pseudônimo Constantin Constantius, esse "maquinador" ou "intrigante estético" do Pós-escrito às migalhas filosóficas, pode-se verificar que o observador psicológico também ocupa uma posição estratégica em sua obra. Isso fica bastante evidente quando Constantin Constantius escreve:

\footnotetext{
Um observador tem de saber fazer-se fácil, senão ninguém se abre com ele; acima de tudo que ele se guarde de ser eticamente rigoroso ou de se apresentar como o indivíduo moralmente sem erro. Este é um homem perdido, diz alguém, passou por muita coisa, tem histórias extravagantes - ergo bem que posso confiar-me a ele, eu que sou muito melhor! (KIERKEGAARD, 2013, p. 88).
}

O psicólogo não pode ser um homem impecável, do contrário não tem como ganhar a confiança do indivíduo a ser psicologizado. Sucede que, em Kierkegaard, o ganho de confiança faz parte de uma estratégia de sedução. De uma sedução recíproca. O que também impede que a relação entre o observador e o observado seja absolutamente fria. Obviamente, sempre está à espreita aqui a relação religiosa entre aquele que confessa e seu confessor, mas também entre o que confessa e seu confidente, para que aquele dê vazão aos sentimentos para entendê-los melhor. Essa situação é colocada de maneira ingênua pelo jovem apaixonado, de $A$ repetição:

Com uma franqueza que suscitava simpatia, confidenciou-me que o motivo para a visita que me fazia era precisar
de um confidente na presença de quem pudesse falar em voz alta consigo próprio, e que o motivo mais imediato
era o facto de temer ficar parado todo o dia junto da rapariga e desse modo acabar por ser um aborrecimento para
ela. Já se tinha posto várias vezes a caminho da casa dela, mas tinha-se sempre obrigado a si mesmo a voltar para
trás. Pediu-me então que fosse dar um passeio de carruagem com ele para o distrair e para ajudar a passar o tempo.
Também eu me sentia nessa disposição; porque a partir do instante em que ele me havia tomado por confidente
podia estar certo de que eu estaria incondicionalmente a seu serviço (KIERKEGAARD, 2008, p. 38).

Como relata o narrador, não há mais frieza possível da parte do observador, porque não se observa com frieza alguém que reza com fervor, diferentemente do que ocorre quando se observa um pregador fazer o mesmo sermão (KIERKEGAARD, 2008, p. 35). A situação se explica do ponto de vista da teoria dialógica de Kierkegaard: o relacionamento entre Constantin Constantius é fruto de uma sedução recíproca, que supõe sempre um desentendimento inicial, um mal-entendido (Misforstaelse), por assim dizer, originário entre eles.

Essa situação de curto-circuito na comunicação se dá no nível que se poderia chamar de romanesco: a trama se constitui da paixão do jovem pela rapariga, de seus suspiros, de suas lágrimas, e de seu desencanto, que leva o grande maquinador a maquinar a perversa trama da sedução da costureirinha, com o fito de afastar 
a rapariga do rapaz. Essa situação romanesca se desdobra no correr do livro em uma situação teatral, para depois voltar a ser romanesca, com as cartas enviadas pelo rapaz a seu confidente silencioso, e a epístola final de Constantin Constantius ao leitor. De modo semelhante ao romance, a atmosfera teatral é fundamental para a construção do livro e para a compreensão do pensamento kierkegaardiano: no teatro, o espectador pode se colocar em todas as situações imagináveis, em todas as disposições de ânimo possíveis. Graças à magia cênica, um jovem é arrebatado

\begin{abstract}
para dentro dessa realidade artificial de modo a poder, como um duplo, ver-se e ouvir-se a si próprio, fragmentar-se em todas as possíveis variações de si mesmo, e contudo de tal maneira que cada variação continua a ser ele mesmo... Só a imaginação está desperta para o seu sonho sobre a personalidade, tudo o mais dorme ainda profundamente. Numa tal autocontemplação da fantasia, o indivíduo não é realmente uma figura, mas uma sombra ou, mais rigorosamente, a figura real está invisivelmente presente e por isso não se contenta em projectar uma só sombra, antes o indivíduo tem uma multiplicidade de sombras que todas elas se parecem com ele e que em cada momento têm igual direito de ser ele mesmo. A personalidade não está ainda descoberta, sua energia limita-se a anunciar-se na paixão da possibilidade [...] (KIERKEGAARD, 2008, p. 58).
\end{abstract}

Analogamente ao que acontece em Kant, a formação individual passa primeiro por essa gama de tonalidades afetivas para adentrar a interioridade ou a moralidade. Como diz o texto na sequência: "a possibilidade do indivíduo vagueia sem rumo na sua própria possibilidade, descobrindo ora uma, ora outra" (KIERKEGAARD, 2008, p. 59). Nos dois casos, há um destino comum para a antropologia e psicologia, que é o de viver nesse mundo da ilusão amorosa, erótica, num mundo de espetáculo (ele alcança seu máximo no Don Giovanni de Mozart), sem o qual, no entanto, não se chega à verdadeira moralidade (no caso do filósofo alemão) nem à religião (no caso do filósofo dinamarquês).

Quaisquer que sejam os caminhos por que a psicologia empírica chegou a eles, tem-se em Moritz, Kant e Kierkegaard três grandes mostras da fecundidade do modelo experimental de criar estratégias para a revelação da psique. Certamente Kierkegaard distorceu o modelo, ao mostrar a impossibilidade do observador absolutamente frio. Mas curiosamente é assim que psicólogo de A repetição é visto pelo jovem apaixonado, que o acusa de "fria e serena sensatez" daquele que tem um "saber oficial" e tramou o seu plano para fazer dele um herói (no sentido romanesco ou teatral), isto é, um patife, um impostor. O jovem amante acusa o observador de querer transformá-lo num ator, de ser um Don Juan. "Infelizmente, diz o jovem, "não fui entretanto artista que tivesse força suficiente para tal prestação..." (KIERKEGAARD, 2008, p. 95). A olhos mais "adultos", a recusa do jovem de se submeter ao jogo cênico proposto pelo psicólogo significa que ele se agarra à ilusão de querer manter a sua inocência intacta e, por isso, na economia do livro, ele não teria conseguido o que interessa, isto é, repetir. Mas a ironia tem mão dupla, e o jovem é, por isso, um dos principais fautores do efeito de desestabilização e incerteza que a obra provoca.

Também não é implausível pensar, por outro lado, que a distorção proposital a que Kierkegaard submete a figura do observador é uma grande homenagem à ideia de psicologia experimental. Seria não entender bem o livro acreditar que ele é o grande maquinador de tudo, que constroi toda a sua trama, do princípio ao fim, incluindo a personagem principal, a jovem amada e a costureirinha, como ele mesmo confessa na carta final ao leitor. Porque Constantin Constantius também se auto-experimenta: ele é levado a viajar de novo a Berlim, a se hospedar no mesmo quarto do apartamento situado no Gendarmenmarkt, de ir ao Königsstädter Theater e depois jantar no mesmo restaurante, sem conseguir repetir. E ele é levado a tudo isso em função do pressentimento que teve quanto às consequências do caso do rapaz. Ele não conseguiu se manter absolutamente frio. Como ele mesmo diz, a posição do observador é "perigosa".

Quando comenta, no Pós-Escrito, essa posição de Constantin, Johannes Climacus afirma que na Repetição espontaneidade e sensatez estão separadas, diferentemente do que ocorre com a experimentação de Frater Taciturnus no Quidam. É que o próprio Constantin precisava participar da trama e assumir papéis nela, enquanto que "Frater Taciturnus fica inteiramente de fora, como um inspetor de polícia". Aqui se vê que 
a experimentação pode oscilar entre o observador frio e o observador participativo. Mas parece que em ambos os casos a situação do observador e do experimentador é a mesma. Como explica Climacus:

Frater Taciturnus se define como ocupando um nível inferior de existência em relação à de Quidam, visto que este tem uma nova imediatidade. Já Constantin não deixava de estar inclinado a isso na relação com o Jovem, mas tinha contudo a sensatez e a ironia de que carecia o Jovem. Comumente, imagina-se isso de outro modo, que o experimentador, o observador, seja superior, ou se situe acima do que o que ele produz. Daí a facilidade em prover resultados. Aqui é o contrário: o sujeito do experimento descobre e demonstra o mais alto, mais alto não no sentido do entendimento e pensamento, mas no sentido da interioridade (KIERKEGAARD, 2013, p. 305).

O experimento está a serviço de algo mais elevado, a interioridade. Ligado a isso, não custa lembrar, por fim, o valor essencial que tem a experimentação na dialética comunicativa de Kierkegaard, como explica o mesmo Johannes Climacus:

O experimento é a consciente e provocadora revogação da comunicação, o que tem sempre importância para um existente que escreve para pessoas existentes, para que a relação não se transforme na de um recitador para recitadores (KIERKEGAARD, 2013, p. 278). 


\section{Referências bibliográficas:}

ARAUJO, Saulo de Freitas. O lugar de Christian Wolff na história da psicologia. In: Universitas psychologica, $11,3,2012$.

BAUMGARTEN, A. G. Principes de la philosophie première. Tradução de Luc Langlois. Paris: Puf, 2014.

FICHTE, J. G. Der Begriff des Wissenschafteslehre. In: J. G. Fichte-Gesamtausgabe, GA I,2: Werke 1793-1795. Stuttgart-Bad Cannstatt: Friedrich Frommann Verlag (Günther Holzboog), 1964.

KANT, Immanuel. Kritik der reinen Vernunft. In: AA 03. Berlim: Reimer, 1911.

. Metaphysik. In: AA 28. Berlim: De Gruyter, 1980.

. Anthropologie Busolt. In: AA 28. Berlim: De Gruyter, 1980.

. Menschenkunde. In: AA 25. Berlim: De Gruyter, 1997.

. Antropologia Friedländer. In: AA 25. Berlim: De Gruyter, 1997.

. Anthropologie Parrow. In: AA 25. Berlim: De Gruyter, 1997.

. Anthropologie Collins. In: AA 25. Berlim: De Gruyter, 1997.

. Anthropologie Pillau. In: AA 25. Berlim: De Gruyter, 1997.

Paulo: Edunesp, 2018

. Lições de ética. Tradução e apresentação de Bruno Cunha e Charles Feldhaus. São

KIERKEGAARD, S. A repetição. Um ensaio em psicologia experimental. Tradução de José Miranda Justo. Lisboa: Relógio d’Água, 2008.

Vozes, 2013.

. Pós-escrito às migalhas filosóficas. Tradução de Álvaro Montenegro Vals. São Paulo:

KRÜGER. Versuch einer Experimental-Seelenlehre. Halle/Helmstädt: Hemmerde, 1756.

MEIER, Georg Friedrich. Theoretische Lehre von den Gemüthsbewegungen. Halle: Hemmerde, 1759.

MORITZ, Karl Philipp. Aussichten zu einer Experimentalseelenlehre. Berlim, Milyus, 1782

Carambaia, 2019.

. Anton Reiser. Um romance psicológico. Tradução de José Feres Sabino. São Paulo:

PLATNER, E. Philosophische Aphorismen. In: J. G. Fichte-Gesamtausgabe, GA IV,4. Stuttgart-Bad Cannstatt: Friedrich Frommann Verlag (Günther Holzboog), 1977.

. Anthropologie für Ärtze und Weltweisei. Leipzig: Dyckische Buchhandlung, 1772.

REIMARUS, Hermann Samuel. Vernunftlehre. In: Hermann Samuel Reimarus Gesammelte Schriften. Munique: Hanser, 1979. 
SPEZZAPRIA, Mario. Kant, Moritz e la Magazin zur Erfahrungs-Seelenkunde. In: Estudos kantianos, 3, 2, 2015.

STIENING, Gideon. Zwischen System und Experiment. Johan Gottlob Krügers Versuch einer ExperimentalSeelenlehre. In: Quaestio, 16, 2016.

SULZER, J. G. Kurzer Begriff aller Wissenschaften. In: Sulzer's gesammelte Schriften, Basileia: Schwab, 2014.

Essais de physique apliquée à l'âme. Tradução de Samuel Formey. In: Mélanges philosophiques. Leiden: Elie Luzac, 1754.

SUZUKI, Márcio. Des Herrn Professors Kants Paradoxon des Comoedianten. In: Kant-Studien, 109, 3, (2018), pp. 395-418.

TOLLE, Oliver. O livro da alma. In: Cadernos de estética aplicada, v. 19, 2016, pp. 60-69.

WOLFF, C. Philosophia rationalis sive Logica. Frankfurt: Rengeriana, 1732.

Psychologia empirica, methodo scientifica pertractata. Frankfurt/Leipzig: Rengeriana, 1738.

Recebido em 30 de junho de 2020. Aceito em 16 de agosto de 2020. 